\title{
Myrtus communis L. (Mersin) Yaprak Ekstraktının Genoprotektif Etkisinin Somatik Mutasyon ve Rekombinasyon Testi (SMART) ile Değerlendirilmesi
}

\author{
Selda ÖZ*, Şükran ÇAKIR ARICA \\ Kırıkkale Üniversitesi, Biyoloji Bölümü, Kırıkkale \\ (ORCID: 0000-0003-1883-3441) (ORCID: 000-0003-1413-1143)
}

\begin{abstract}
$\ddot{O} z$
Bu çalışmada Myrtus communis L. (mersin) yaprak ekstraktının genoprotektif etkisi somatik mutasyon ve rekombinasyon testi (SMART) ile incelendi. Yüksek genotoksik etkiye sahip kemoterapötik bir ajan olan doksorubisin (DXR) pozitif kontrol olarak kullanıldı. Test maddeleri flare $\left(f l r^{3}\right)$ ve çoklu kanat kılı $(m w h)$ mutant işaret genlerini taşıyan üç günlük ( $72 \pm 4$ saat) transheterozigot Drosophila melanogaster larvalarına uygulandı. Mersin yaprak ekstraktı, genotoksik etkisini değerlendirmek için tek başına $(1,5 \mathrm{ve} 10 \mathrm{mg} / \mathrm{ml})$, antigenotoksik etkisini değerlendirmek için doksorubisin $(0,125 \mathrm{mg} / \mathrm{ml})$ ile uygulandı. İnhibisyon yüzdeleri $1,5 \mathrm{ve} 10 \mathrm{mg} / \mathrm{ml}$ dozlarında sırasıyla \%91,70, \%97,51 ve \%98,34 olarak hesaplandı. Bu çalışmadan elde edilen sonuçlara göre mersin yaprak ekstraktı test edilen tüm dozlarda doksorubisin kaynaklı mutant klon oluşumunu inhibe ederek antigenotoksik etki gösterdi.
\end{abstract}

Anahtar kelimeler: Myrtus communis L., antigenotoksisite, doksorubisin, Drosophila melanogaster.

\section{Assessing the Genoprotective Effect of Myrtus communis L. (Myrtle) Leaf Extract by Somatic Mutation and Recombination Test (SMART)}

\begin{abstract}
In this study genoprotective effect of Myrtus communis L. (myrtle) leaf extract was investigated with somatic mutation and recombination test (SMART). Doxorubicin (DXR), a chemotherapeutic agent with high genotoxic effect, was used as a positive control. The test substances were administered to three-day-old ( $72 \pm 4$ hours) transheterozygous Drosophila melanogaster larvae carrying genetic markers flare $\left(f l r^{3}\right)$ and multiple wing hair $(m w h)$. Myrtle leaf extract was applied alone $(1,5$ and $10 \mathrm{mg} / \mathrm{ml})$ to evaluate its genotoxic effect and in combination with doxorubicin $(0,125 \mathrm{mg} / \mathrm{ml})$ to evaluate its antigenotoxic effect. Inhibition percentages were calculated as $91,70 \%, 97,51 \%$ and $98,34 \%$ at 1,5 and $10 \mathrm{mg} / \mathrm{ml}$ doses, respectively. The results obtained from this study revealed that myrtle leaf extract showed antigenotoxic effect by inhibiting doxorubicin-induced mutant clone formation at all doses tested.
\end{abstract}

Keywords: Myrtus communis L., antigenotoxicity, doxorubicin, Drosophila melanogaster.

\section{Giriş}

Günümüzde teknoloji ve endüstrinin ilerlemesi ile değişen yaşam koşulları ve beslenme alışkanlıkları sonucu insanlar günlük hayatta pek çok kimyasal ve fiziksel ajana maruz kalmaktadır. İnsan vücudunda genotoksik ajanların zararlı etkilerini önleyecek detoksifikasyon mekanizmaları bulunmasına rağmen, zaman zaman bu mekanizmalarda aksaklıklar meydana gelebilir ve bu ajanların olumsuz etkileri önlenemeyebilir [1]. Bu durumda söz konusu ajanlar gen ve kromozomların yapısında ve sayısında değişikliğe yol açarak bireylerde genotoksisite oluşumuna neden olabilir.

"Sorumlu yazar: seldaoz@kku.edu.tr

Geliş Tarihi: 13.06.2019, Kabul Tarihi: 20.08.2019 
Antigenotoksinler, genotoksik ajanların etkilerini önleme veya azaltma yeteneğine sahip olan maddelerdir. Bitkilerde bulunan fenolik bileşenler, flavonoidler, alkoidler gibi çeşitli fitokimyasalların antigenotoksik özelliğe sahip olduğu bilinmektedir [2-4]. Yapılan araştırmalarda organizmalarda doğal olarak bulunan detoksifikasyon mekanizmalarının yanı sıra vücuda beslenme yolu ile alınan antigenotoksik etkiye sahip fitokimyasalların genotoksinlerin zararlı etkilerini önlemekte etkili oldukları gösterilmiştir [5,6].

Mersin bitkisi Myrtaceae familyasından, Akdeniz Havzası'nda yetişen, küçük mavi-siyah renkte meyvelere ve yaz kış yeşil kalan aromatik yapraklara sahip çalı formunda bir bitkidir. Bitkinin yaprak, meyve ve çiçek gibi farklı kısımlarının sinüzit, hemoroid, diyare, ülser, inflamasyon, deri rahatsızlıkları ile solunum, sindirim ve üriner sistemlerdeki rahatsızlıkların tedavisine yönelik olarak alternatif tıpta kullanıldığı bilinmektedir. İçerdiği esansiyel yağlar nedeniyle aromatik özellikte olan mersin bitkisi tedavi amaçlı kullanımın yanı sıra gıdaları koruma, aroma verme amacıyla da eski zamanlardan beri kullanılmaktadır [7-9]. Fitokimyasal analizler sonucunda mersin yapraklarının fenolik bileşenler (gallik asit, ellajik asit, tanen), flavonoidler (kuersetin, kateşin, mirisetin ve kaempferol), uçucu yağlar (mirtenil asetat, 1,8-sineol, $\alpha$-pinen, linalol, linalil asetat, limonen), antosiyanin pigmentleri ile güçlü antioksidan özellikleri olan mirtukomulon-A ve semimirtukomulon bileşiklerini içerdiği tespit edilmiştir [8-11].

Antigenotoksisitenin değerlendirilmesinde kullanılan doksorubisin, kanser tedavisinde yaygın olarak kullanılan antrasiklin türevi bir antibiyotiktir [12]. Reaktif oksijen türevleri (ROS) üretimi, topoizomeraz II inhibisyonu, DNA interkalasyonu gibi çeşitli mekanizmalarla antikarsinojen etki oluşturan doksorubisin, normal hücreler üzerinde de genotoksik etkiye neden olmaktadır [13]. Daha önce yapılan pek çok antigenotoksisite çalışmasında doksorubisin genotoksik ajan olarak kullanılmış ve Drosophila melanogaster için $\mathrm{LD}_{50}$ değeri $0,125 \mathrm{mg} / \mathrm{ml}$ olarak belirlenmiştir [14,15].

$\mathrm{Bu}$ çalışmada mersin yaprak ekstraktının güçlü bir genotoksin olan doksorubisine karş1 antigenotoksik etkisi Drosophila melanogaster'de somatik mutasyon ve rekombinasyon testi (SMART) ile değerlendirilmiş̧ir. SMART Drosophila melanogaster'de bulunan $m w h$ ve flr işaret genlerindeki heterozigotluk kaybını temel alan, in vivo olarak yürütülen bir analizdir. Kısa zamanda, kolay ve ekonomik olarak güvenilir veriler sağlaması nedeniyle genotoksisite araştırmalarında sıklıkla tercih edilmektedir [16-18].

\section{Materyal ve Metot}

\subsection{Test Materyalleri}

Çalışmada kullanılan mersin yaprak örnekleri 2014 yılı Kasım ayında Hatay ili, İskenderun ilçesi, Güzelköy sınırları içerisinde bulunan, yerleşim yerlerinden ve yoldan uzak dăg eteklerinden toplandı. Örnekler kurutulup porselen havanda toz haline getirildikten sonra etanol ile (w:v; 1:10) yatay çalkalayıcıda (125 rpm), oda sıcaklığında 24 saat süre ile ekstrakte edildi. Ekstraksiyon filtreden geçirildikten sonra rotary evaporatör (Bucchi Rotavapor R-210) ile etanol uzaklaştırıldı. Elde edilen ekstrakt deneylerde kullanılana kadar $+4{ }^{\circ} \mathrm{C}$ 'de koyu renkli şişelerde muhafaza edildi. Pozitif kontrol olarak doksorubisin (Santa Cruz Biotechnology, CA, USA), negatif kontrol olarak distile su kullanıldı. Mersin yaprak ekstraktı ve doksorubisin denemelerden hemen önce distile su kullanılarak çözüldü.

\subsection{Uygulama}

Drosophila melanogaster'in flare-3 (flr $\left.{ }^{3} / \mathrm{In} \quad(3 L R), \quad T M 3 \quad B d^{S}\right)$ 1rkına ait 1-3 günlük virgin (çiftleşmemiş) dişiler ile multiple wing hairs $(m w h / m w h)$ ırkına ait aynı yaştaki erkek bireyler arasında yapılan standart çaprazdan elde edilen $72 \pm 4$ saatlik transheterozigot larvalar standart besi ortamından ayrılıp yıkandıktan sonra, $5 \mathrm{ml}$ test solüsyonu ile 1slatılmıs 1,5 g hazır Drosophila besiyeri (Instant Drosophila Medium Formula 4-24, Carolina Biological Supply Co., Burlington, NC, USA) içeren cam şişelere aktarıldı. Her test grubunda 100 larvaya uygulama yapıldı ve her uygulama $3 \mathrm{kez}$ tekrar edildi. Mersin yaprak ekstraktı, genotoksik etkisinin değerlendirilmesi için 1,5 ve $10 \mathrm{mg} / \mathrm{ml}$ dozlarında tek olarak, antigenotoksik etkisinin değerlendirilmesi için her bir dozu $0,125 \mathrm{mg} / \mathrm{ml}$ doksorubisin ile kombine olarak uyguland. Larvalar negatif kontrol denemelerinde distile su eklenmiş besiyerinde, pozitif kontrol denemelerinde $0,125 \mathrm{mg} / \mathrm{ml}$ doksorubisin eklenmiş besiyerinde geliştirildi. Stoklar ve 
uygulama grupları $25 \pm 1{ }^{\circ} \mathrm{C}$ ve \%40-60 nem içeren etüvlerde tutuldu. Pupadan çıan ergin bireylerden fenotipik olarak normal kanat şekline sahip olanlar preparasyon için ayrıldı. Seçilen bireyler \%70 etanol bulunan şişelere alınarak kanat preparatları yapılana kadar $+4^{\circ} \mathrm{C}$ 'de saklandı $[16,19]$.

\subsection{Kanatların mikroskobik analizi}

Bireylerin kanatları pens yardımı ile gövdeden ayrılıp lam üzerine yerleştirildikten sonra Entellan (Merck) ile lam üzerine sabitlendi. Her bir uygulama için 40 bireyin kanadı incelenerek mutant klonlar kaydedildi. İncelenen kanatlardaki mutant klonların değerlendirilmesi ve sınıflandırılmasında Graf vd. [16] tarafından yapılan çalışma esas alındı. Bu çalışmaya göre mutant hücre kümesinde 1-2 $m w h$ varsa küçük tek tip klon, 3 veya daha fazla $m w h$ ya da 4 veya daha fazla $f l{ }^{3}$ varsa büyük tek tip klon, $m w h$ ve $f l r^{3}$ fenotipleri birlikte bulunuyorsa ikiz klon olarak adlandırılmıștır. Tek tip klonlar nokta mutasyon, delesyon, ayrılmama ve iki belirleyici gen ( $m w h$ ve $\left.f l r^{3}\right)$ arasindaki mitotik rekombinasyonla oluşurken ikiz klonlar üçüncü kromozomun sentromeri ile $f l r^{3}$ geni arasındaki mitotik rekombinasyon sonucu oluşmaktadır [16].

\section{4. İstatistiksel Analiz}

Mersin yaprak ekstraktı uygulanan gruplardan elde edilen veriler genotoksik etkinin değerlendirilmesinde su kontrol grubu ile antigenotoksik etkinin değerlendirilmesinde doksorubisin kontrol grubu ile şartlı binomial test kullanılarak \%5 güven aralığında analiz edildi [20]. Elde edilen sonuçlar istatistiksel olarak negatif, pozitif veya önemsiz olarak belirlendi [21]. Antigenotoksik etkinin değerlendirilmesinde kullanılan inhibisyon yüzdesi aşağıdaki formüle göre hesaplandı [22].

$$
\% \text { İnhibisyon }=[(a-b) / a] \times 100
$$

$\mathrm{Bu}$ formülde "a" doksorubisin uygulamasindaki toplam klon frekansını, "b" doksorubisin ve yaprak ekstraktının birlikte uygulamasındaki toplam klon frekansını göstermektedir.

\section{Bulgular ve Tartışma}

$\mathrm{Bu}$ çalışmada mersin yaprak ekstraktının genotoksik etkisi ile doksorubisine karşı genoprotektif etkisi Drosophila melanogaster'de SMART ile incelendi. Genotoksik ve antigenotoksik etkilerin değerlendirilmesi sonucu elde edilen veriler Tablo 1 ve Tablo 2'de özetlendi.

Mersin yaprak ekstraktının genotoksik etkisinin değerlendirilmesi için ekstrakt 1,5 ve 10 $\mathrm{mg} / \mathrm{ml}$ dozlarında uygulandı. Uygulama gruplarında gözlenen her bir mutant klonun frekans1 su kontrol grubunda gözlenenlerle kıyaslandığında istatistiksel olarak önemli farklılığa rastlanmadı $(\mathrm{p}>0.05)$. Elde edilen veriler mersin yaprak ekstraktının uygulanan dozlarda herhangi bir genotoksik etkiye neden olmadığını gösterdi (Tablo1).

Tablo 1. Mersin yaprak ekstraktının farklı dozlarının transheterozigot D. melanogaster larvalarında genotoksik etkisinin değerlendirilmesi

\begin{tabular}{|c|c|c|c|c|c|c|c|c|c|c|c|c|c|c|c|c|c|}
\hline \multirow[t]{2}{*}{$\begin{array}{l}\text { Uygulama } \\
(\mathrm{mg} / \mathrm{ml})\end{array}$} & \multirow[t]{2}{*}{$\begin{array}{c}\text { Kanat } \\
\text { Say1s1 } \\
(\mathrm{N})\end{array}$} & \multicolumn{3}{|c|}{$\begin{array}{c}\text { Küçük tek tip } \\
\text { klon } \\
(1-2 \text { hücre }) \\
(m=2)\end{array}$} & \multicolumn{3}{|c|}{$\begin{array}{c}\text { Büyük tek tip } \\
\text { klon } \\
(>2 \text { hücre }) \\
(m=5)\end{array}$} & \multicolumn{3}{|c|}{$\begin{array}{l}\text { İkiz klon } \\
\quad(m=5)\end{array}$} & \multicolumn{3}{|c|}{$\begin{array}{l}\text { Toplam } m w h \text { klon } \\
\qquad(m=2)\end{array}$} & \multicolumn{3}{|c|}{$\begin{array}{l}\text { Toplam klon } \\
\qquad(m=2)\end{array}$} & \multirow[t]{2}{*}{$\mathrm{F}$} \\
\hline & & No & $\mathrm{Fr}$ & $\mathrm{D}$ & No & $\mathrm{Fr}$ & $\mathrm{D}$ & No & $\mathrm{Fr}$ & D & No & $\mathrm{Fr}$ & D & No & $\mathrm{Fr}$ & D & \\
\hline Distile su & 80 & 7 & 0,09 & & 3 & 0,04 & & 1 & 0,01 & & 11 & 0,14 & & 11 & 0,14 & & 0,56 \\
\hline \multicolumn{18}{|l|}{ Dxr } \\
\hline 0,125 & 80 & 122 & 1,53 & + & 52 & 0,65 & + & 19 & 0,24 & + & 183 & 2,29 & + & 193 & 2,41 & + & 9,38 \\
\hline \multicolumn{18}{|l|}{ MYE } \\
\hline 1 & 80 & 6 & 0,08 & $\mathrm{i}$ & 2 & 0,03 & - & 0 & 0,00 & $\mathrm{i}$ & 8 & 0,10 & - & 8 & 0,10 & - & 0,41 \\
\hline 5 & 80 & 9 & 0,11 & $\mathrm{i}$ & 0 & 0,00 & - & 0 & 0,00 & $\mathrm{i}$ & 9 & 0,11 & - & 9 & 0,11 & - & 0,46 \\
\hline 10 & 80 & 2 & 0,03 & - & 2 & 0,03 & - & 0 & 0,00 & $\mathrm{i}$ & 3 & 0,04 & - & 4 & 0,05 & - & 0,15 \\
\hline
\end{tabular}

F: klon indüksiyon frekansı (10 $0^{5}$ hücre), Dxr: doksorubisin, MYE: mersin yaprak ekstrakt1, No: klon sayıs1, Fr: frekans, D: istatistiksel değerlendirme sonucu [21]; -: negatif fark, i: önemsiz fark, m: çarpım faktörü; olasılık düzeyi: $\alpha=\beta=0,05$ 
Denemelerde pozitif kontrol olarak doksorubisin $(0,125 \mathrm{mg} / \mathrm{ml})$ uygulamas1 sonucu su kontrol grubuna göre mutant klon frekanslarında artış gözlendi, bu artış istatistiksel olarak değerlendirildiğinde anlamlı bulundu $(\mathrm{p}<0,05)$. Elde edilen veriler daha önce yapılan çalışmalarla $[14,15]$ uyumlu olarak doksorubisinin genotoksik etkiye neden olduğunu gösterdi (Tablo 1).

Mersin yaprak ekstraktının antigenotoksik etkisinin değerlendirilmesi için, ekstraktın her bir dozu $0,125 \mathrm{mg} / \mathrm{ml}$ doksorubisin ile kombine olarak uygulandı. Bu uygulamadan elde edilen sonuçlar pozitif kontrol olarak kullanılan doksorubisin uygulamasına ait sonuçlar ile karşılaştırıldığında mutant klon frekanslarında istatistiksel olarak önemli derecede azalma olduğu saptandı. Ekstraktın 1,5 ve 10 $\mathrm{mg} / \mathrm{ml}$ dozlarında uygulanması sonucu gözlenen inhibisyon değerleri sirasıyla \%91,70, \%97,51 ve $\% 98,34$ oldu. Bu verilere göre mersin yaprak ekstraktı uygulanan her üç dozda doksorubisinin neden olduğu genotoksik etkiyi yüksek oranda $(>\% 90)$ engelleyerek güçlü antigenotoksik etki gösterdi ve ekstraktın engelleyici etkisi doza bağlı olarak arttı (Tablo 2).

Tablo 2. Mersin yaprak ekstraktının farklı dozlarının transheterozigot D. melanogaster larvalarında antigenotoksik etkisinin değerlendirilmesi

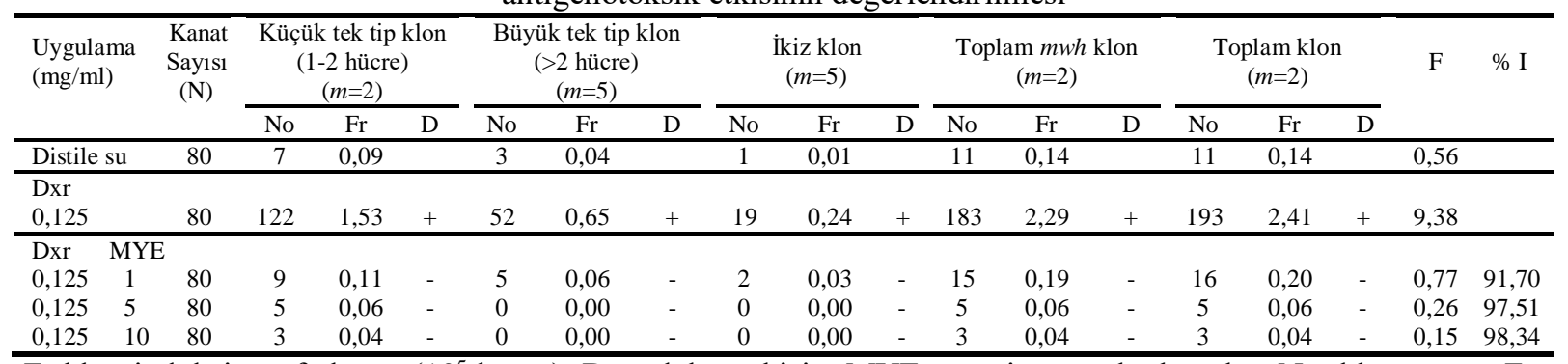

F: klon indüksiyon frekansı (10 ${ }^{5}$ hücre), Dxr: doksorubisin, MYE: mersin yaprak ekstrakt1, No: klon say1sı, Fr: frekans, I: inhibisyon yüzdesi D: istatistiksel değerlendirme sonucu [21]; -: negatif fark, i: önemsiz fark, m: çarpım faktörü; olasılık düzeyi: $\alpha=\beta=0,05$

Doksorubisin kanser tedavisinde yaygın kullanılan bir ilaç olmakla birlikte, normal hücreler üzerinde genotoksik etkiye neden olması kullanımını sınırlandırmaktadır. Antrasiklin grubundan olan diğer ilaçlarda olduğu gibi doksorubisinin metabolizasyonu sonucunda hücrede fazla miktarda ROS üretimi meydana gelmektedir [23-24]. Açığa çıkan ROS kanser hücrelerinin yanı sıra kalp, karaciğer, böbrek ve üreme organlarında da toksik etkiye neden olmaktadır [25-27]. Doksorubisinin toksik etkisinin bitki ekstraktları ve bitkisel bileşenlerin kullanımı ile giderilmesi pek çok araştırmanın konusu olmuştur. Bu çalışmalarda çeşitli bitki ekstrakt ve bileşenlerinin gösterdikleri antioksidan etkinin doksorubisinin neden olduğu toksisiteyi önlemede etkili olduğu bildirilmiştir. Gao vd. [28] Ginkgo biloba yaprak ekstraktında bulunan Ginkgolide B bileşeninin, ROS düzeyini düşürerek doksorubisinin neden olduğu kardiyotoksisiteye karşı koruyucu etki sağladığını göstermişlerdir. Nigella sativa ve Curcuma longa ekstraktlarının doksorubisin uygulaması sonucu böbrek hasarı meydana gelen ratlarda süperoksit dismutaz ve toplam tiyol konsantrasyonlarında artışa neden olarak antioksidan etki sağladıkları bildirilmiştir [29]. Diğer bir çalışmada Curcuma longa ekstraktının karaciğer dokusunda da doksorubisinin toksisitesine karşı koruyucu etki sağladığı gösterilmiştir [30]. Doğal bir flavonoid olan morinin doksorubisine karşı koruyucu etkisinin araştırıldığı çalışmada, böbrek ve karaciğer dokularında antioksidan etkinin göstergesi olan glutatyon ve malondialdehid biyobelirteçlerinin düzeyleri ile superoksit dismutaz, katalaz ve glutatyon peroksidaz enzimlerinin aktiviteleri incelenmiştir. Yapılan değerlendirmeler sonucunda morin ön uygulaması ile doksorubisin kaynaklı böbrek ve karaciğer hasarının önlenebileceği gösterilmiştir [31].

Mersin yaprak ekstraktı ile daha önce yürütülen araştırmalarda, ekstraktın antioksidan etkili fenolik bileşenler, flavonoidler ve esansiyel yağlar bakımından zengin olduğu tespit edilmiştir [32-35]. Hayder vd. [36] çalışmalarında mersin yaprak ekstraktında bulunan flavonoidlerden mirisetin-3-ogalaktozid ve mirisetin-3-o-ramnozidin oksidadif stres ve DNA onarımında rol oynayan genlerin ifadesini etkileyerek antioksidan ve antigenotoksik etki gösterdiklerini bildirmiştir. Rosa vd. [37] mersin yaprak ekstraktında bulunan mirtukomulon A ve semimirtukomulon bileşiklerinin in vitro ortamda serbest radikallerin neden olduğu linoik asit oksidasyonunu önlediklerini rapor etmişlerdir. Çalışmada antioksidatif etkisinin daha güçlü olduğu saptanan semimirtukomulon ile yapılan in vivo deneylerde bileşik lipid peroksidasyonunu önlemiş, ayrıca insan embriyonik akciğer fibroblastı 
(HELF) hücre hattında oksidadif strese karşı koruyucu etki sağlamıştır. Diğer bir çalışma [38], mirtukomulon A ve semimirtukomulon bileşiklerinin LDL, çoklu doymuş yağ asitleri ve kolesterolün oksidasyonuna karşı koruyucu etki sağladıklarını göstermiştir. Ines vd. [39] mersin yaprağında bulunan bileşiklerden 3,5-O-di-galloilkuinik asidin (DGQA), kronik miyeloid lösemi (K562) hücre hattında $\mathrm{H}_{2} \mathrm{O}_{2}$ ile indüklenen lipid peroksidasyonunu ve genotoksisiteyi engelleyerek antioksidan ve antigenotoksik etki gösterdiğini kaydetmişlerdir. Mersin yaprağında bulunduğu bildirilen bir flavonoid olan kaempferol ile yapılan çalışmalar bu bileşenin beslenme yoluyla alındığında kanser başta olmak üzere, kronik hastalıklara yakalanma riskini azalttığını göstermiştir [40]. Ayrıca Khalil vd. [27] mersin yaprak ekstraktının doksorubisine karşı koruyucu etkisini erkek albino farelerin sperm hücrelerinde inceledikleri çalışmalarında ekstraktın DNA fragmentasyonu ve hasarı ile kromozom aberasyonunu azalttığını rapor etmiştir.

Amensour vd. [32] yaptıkları analiz sonucunda mersin bitkisi yaprağının flavonoid içeriğinin mersin meyvesine göre daha yüksek olduğunu saptamışlardır. Mersin meyve ekstraktının doksorubisine karşı koruyucu etkisini Drosophila melanogaster'de incelediğimiz diğer bir çalışmada [41] ekstraktın 1, 5 ve $10 \mathrm{mg} / \mathrm{ml}$ dozlarında uygulanması sonucu doksorubisinin $(0,125 \mathrm{mg} / \mathrm{ml})$ neden olduğu genotoksisiteyi sırasıyla $\% 86, \% 88$ ve $\% 90$ oranında inhibe ettiği gözlenmiştir. Mersin yaprak ve mersin meyve ekstraktlarının antigenotoksik etkilerini incelediğimiz iki çalışma karşılaştırıldığında, mersin yaprak ekstraktının doksorubisinin genotoksik etkisine karşı daha yüksek oranda inhibisyon gösterdiği görülmektedir. Amensour vd. [32] tarafından yapılan çalışma göz önüne alındığında mersin yaprak ekstraktının meyve ekstraktından daha yüksek antigenotoksik etki göstermesinin nedeni olarak flavonoid içeriğinin daha yüksek olması düşünülebilir.

Mersin yaprak ekstraktının hangi mekanizmalarla doksorubisine karşı antigenotoksik etki oluşturduğu çalışmamızda incelenmemiş olmakla birlikte daha önce yapılmış olan çalışmalardan elde edilen veriler 1şı̆̆ında ekstraktın içerdiği fenolik bileşenler, flavonoidler, esansiyel yağlar gibi antioksidan özellikteki bileşenler aracılığı ile doksorubisinin metabolizasyonu sonucu açığa çıkan ROS'ni inhibe ederek antigenotoksik etki yarattığı düşünülebilir.

\section{Sonuç ve Öneriler}

İnsanlar günlük yaşamlarında beslenme, soluma, temas gibi yollarla direkt ya da dolaylı olarak birçok genotoksik ajana maruz kalmaktadır. Genetik materyalde onarılmaz değişikliklere ve bunun sonucunda da genotoksisiteye neden olan genotoksik ajanlar vücuda girdiklerinde çeşitli detoksifikasyon mekanizmaları bu ajanları etkisiz hale getirme yoluna gitmektedir. Fakat bireyin genotoksik ajanlara sık ve uzun süreli maruz kalması sonucu söz konusu mekanizmalar yetersiz kalabilmektedir. $\mathrm{Bu}$ durumda dışarıdan alınan antigenotoksik maddeler vücudu genotoksik ajanlara karşı savunmada destek sağlayıcı olabilir.

Bu çalışmada mersin yaprak ekstraktının beslenme yolu ile vücuda alınması sonucu güçlü bir genotoksik ajan olan doksorubisinin etkisini kuvvetli biçimde engellediği gösterilmiştir. Genotoksik etkisi güçlü bir ilaç olan doksorubisine karşı koruyucu etkisi gösterilmiş mersin yaprak ekstratının bileşenleri incelenerek bu bileşenlerin koruyucu tıpta kullanımına yönelik yeni çalışmalar yapılabilir. Ayrıca antioksidan ve aromatik özellikler taşıdığı bilinen mersin yaprağından elde edilen ekstrakt ve ekstrakt içerisinde bulunan bileşenler aroma verme, oksidasyonu önleme gibi amaçlarla doğal katkı maddesi olarak kullanılarak gidalar fonksiyonel hale getirilebilir. Mersin yaprak ekstraktı gida takviyesi olarak alınarak vücutta antioksidan ve oksidan maddeler arasındaki dengenin sağlanmasında ve genotoksik ajanların etkilerine karşı vücuda destek sağlanmasında yardımcı olarak kullanılabilir.

\section{Teşekkür}

$\mathrm{Bu}$ çalışma Kırıkkale Üniversitesi Bilimsel Araştırma Projeleri Koordinasyon Birimi tarafindan desteklenmiştir (Proje No: 2012/010).

\section{Kaynaklar}

[1] Liska D.J. 1998. The Detoxification Enzyme Systems Alternative Medicine Review, 33 (3): 187-198. 
[2] Bacanlı M., Başaran A.A., Başaran N. 2015. The antioxidant and antigenotoxic properties of citrus phenolics limonene and naringin. Food and Chemical Toxicology, 81: 160-170.

[3] Goswami P., Banerjee R., Mukherjee A. 2019. Potential antigenotoxicity assessment of Ziziphus jujuba fruit, Heliyon, 5 (5): e01768.

[4] Lozano-Baena M.D., Tasset I., Obregón-Cano S., de Haro-Bailon A., Muñoz-Serrano A., Alonso-Moraga Á. 2015. Antigenotoxicity and tumor growing inhibition by leafy Brassica carinata and sinigrin. Molecules, 20 (9): 15748-15765.

[5] Munari C.C., de Oliveira P.F., Leandro L.F., Pimenta L.M., Ferreira N.H., da Costa J de C., Bastos J.K., Tavares D.C. 2014. In vivo assessment of genotoxic, antigenotoxic and anticarcinogenic activities of Solanum lycocarpum fruits glycoalkaloidic extract. PLoS One, 9 (11): e111999.

[6] Qiu Z., Tang M., Deng G., Yang H., Zhang X., Huang S., Wu L. 2014. Antioxidant and antigenotoxic activities of ethanol extracts from Rhus chinensis Mill leaves. Food Science and Biotechnology, 23 (4): 1213-1221.

[7] Aleksic V., Knezevic P. 2014. Antimicrobial and antioxidative activity of extracts and essential oils of Myrtus communis L. Microbiological Research, 169 (4): 240-254.

[8] Alipour G., Dashti S., Hosseinzadeh H. 2014. Review of Pharmacological Effects of Myrtus communis L. and its Active Constituents. Phytotherapy Research, 28 (8): 1125-1136.

[9] Bouzabata A., Cabral C., Gonçalves M.J., Cruz M.T., Bighelli A., Cavaleiro C., Casanova J., Tomi F., Salgueiro L. 2015. Myrtus communis L. as source of a bioactive and safe essential oil. Food and Chemical Toxicology, 75: 166-172.

[10] Aidi Wannes W., Mhamdi B., Sriti J., Ben Jemia M., Ouchikh O., Hamdaoui G., Kchouk M.E., Marzouk B. 2010. Antioxidant activities of the essential oils and methanol extracts from myrtle (Myrtus communis var. italica L.) leaf, stem and flower. Food and Chemical Toxicology, 48 (5): 1362-1370.

[11] Cherrat L., Espina L., Bakkali M., García-Gonzalo D., Pagán R., Laglaoui A. 2014. Chemical composition and antioxidant properties of Laurus nobilis L. and Myrtus communis L. essential oils from Morocco and evaluation of their antimicrobial activity acting alone or in combined processes for food preservation. Journal of the Science of Food and Agriculture, 94 (6): 11971204.

[12] Malla S., Prasad Niraula N., Singh B., Liou K., Sohng J.K. 2010. Limitations in doxorubicin production from Streptomyces peucetius. Microbiological Research, 165 (5): 427-435.

[13] Meredith A.M., Dass C.R. 2016. Increasing role of the cancer chemotherapeutic doxorubicin in cellular metabolism. Journal of Pharmacy and Pharmacology, 68 (6): 729-741.

[14] Saturnino R.S., Machado N.M., Lopes J.C., Nepomuceno J.C. 2018. Assessment of the mutagenic, recombinogenic, and carcinogenic potential of amphotericin B in somatic cells of Drosophila melanogaster. Drug and chemical toxicology, 41 (1): 9-15.

[15] Orsolin P.C., Silva-Oliveira R.G., Nepomuceno J.C. 2016. Modulating effect of simvastatin on the DNA damage induced by doxorubicin in somatic cells of Drosophila melanogaster. Food and Chemical Toxicology, 90: 10-17.

[16] Graf U., Würgler F.E., Katz A.J., Frei H., Juan H., Hall J.V. 1984. Somatic Mutation and Recombination Test in Drosophila melanogaster. Enviromental Mutagenesis, 6 (2): 153-188.

[17] Graf U., Abraham S.K., Guzmán-Rincón J., Würgler F.E. 1998. Antigenotoxicity studies in Drosophila melanogaster. Mutation Research/Genetic Toxicology, 402 (1-2): 203-209.

[18] Mollet P., Würgler F.E. 1974. Detection of somatic recombination and mutation in Drosophila. A method for testing genetic activity of chemical compounds,. Mutation Research/Fundamental and Molecular Mechanisms of Mutagenesis, 25 (3): 421-424.

[19] Graf U., Frei H., Kagi A., Katz A.J., Würgler F.E. 1989. Thirty compounds tested in the Drosophila wing spot test. Mutation Research/Genetic Toxicology, 222 (4): 359-373.

[20] Kastenbaum M.A., Bowman, K.O. 1970. Tables for determining the statistical significance of mutation frequencies. Mutation Research, 9 (5): 527-549.

[21] Frei H., Würgler, F.E. 1988. Statistical methods to decide whether mutagenicity test data from Drosophila assays indicate a positive, negative, or inconclusive result. Mutation Research/Environmental Mutagenesis and Related Subjects, 203 (4): 297-308. 
[22] Abraham S.K. 1994. Antigenotoxicity of coffee in the Drosophila assay for somatic mutation and recombination. Mutagenesis, 9 (4): 383-386.

[23] Xue H., Ren W., Denkinger M., Schlotzer E., Wischmeyer P.E. 2015. Nutrition Modulation of Cardiotoxicity and Anticancer Efficacy Related to Doxorubicin Chemotherapy by Glutamine and $\omega-3$ Polyunsaturated Fatty Acids. Journal of Parenteral and Enteral Nutrition, 40 (1): 52-66.

[24] Asensio-López M.C., Soler F, Sánchez-Más J, Pascual-Figal D, Fernández-Belda F, Lax A. 2016. Early oxidative damage induced by doxorubicin: source of production, protection by GKT137831 and effect on $\mathrm{Ca}^{2+}$ transporters in HL-1 cardiomyocytes, Archives of Biochemistry and Biophysics, 594: 26-36.

[25] Injac R., Perse M., Cerne M., Potocnik N., Radic N., Govedarica B., Djordjevic A., Cerar A., Strukelj B. 2009. Protective effects of fullerenol C $60(\mathrm{OH}) 24$ against doxorubicin-induced cardiotoxicity and hepatotoxicity in rats with colorectal cancer. Biomaterials, 30 (6): 1184-1196.

[26] Yilmaz S., Atessahin A., Sahna E., Karahan I., Ozer S. 2006. Protective effect of lycopene on adriamycin-induced cardiotoxicity and nephrotoxicity. Toxicology, 218 (2): 164-171.

[27] Khalil W.K., Abidli N., Ghaly I.S., Hassanane M.M., Sharafeldin E.A. 2015. Myrtus Species Prevents Reproductive Toxicity Induced By Doxorubicin In Male Mice. Asian Journal of Pharmaceutical and Clinical Research, 8 (3): 169-175.

[28] Gao J., Chen T., Zhao D., Zheng J., Liu Z. 2016. Ginkgolide B exerts cardioprotective properties against doxorubicin-induced cardiotoxicity by regulating reactive oxygen species, Akt and calcium signaling pathways in vitro and in vivo. PloS one, 11 (12): e0168219.

[29] Mohebbati R., Shafei M.N., Soukhtanloo M., Roshan N.M., Rad A.K., Anaeigoudari A., Hosseinian S., Karimi S., Beheshti F. 2016. Adriamycin-induced oxidative stress is prevented by mixed hydro-alcoholic extract of Nigella sativa and Curcuma longa in rat kidney. Avicenna Journal of Phytomedicine, 6 (1): 86-94.

[30] Khazdair M.R., Mohebbati R., Karimi S., Abbasnezhad A., Haghshenas M. 2016. The protective effects of Curcuma longa extract on oxidative stress markers in the liver induced by Adriamycin in rat. Physiology and Pharmacology, 20 (1): 31-37.

[31] Kuzu M., Yıldırım S., Kandemir F.M., Küçükler S., Çağlayan C., Türk E., Dörtbudak M.B. 2019. Protective effect of morin on doxorubicin-induced hepatorenal toxicity in rats. Chemicobiological interactions, 308: 89-100.

[32] Amensour M., Sendra E., Abrini J., Pérez-Alvarez J.A., FernándezLópez J. 2010. Antioxidant activity and total phenolic compounds of myrtle extracts. CyTA-Journal of Food, 8 (2): 95-101.

[33] Babou L., Hadidi L., Grosso C., Zaidi F., Valentão P., Andrade P. B. 2016. Study of phenolic composition and antioxidant activity of myrtle leaves and fruits as a function of maturation. European Food Research and Technology, 242 (9): 1447-1457.

[34] Díaz-de-Cerio E., Arráez-Román D., Segura-Carretero A., Ferranti P., Nicoletti R., Perrotta G. M., Gómez-Caravaca A.M. 2018. Establishment of pressurized-liquid extraction by response surface methodology approach coupled to HPLC-DAD-TOF-MS for the determination of phenolic compounds of myrtle leaves. Analytical and bioanalytical chemistry, 410 (15): 35473557.

[35] Mimica-Dukić N., Bugarin D., Grbović S., Mitić-Ćulafić D.,Vuković-Gačić B., Orčić D., Jovin E., Couladis M. 2010. Essential Oil of Myrtus communis L. as a Potential Antioxidant and Antimutagenic Agents. Molecules, 15: 2759-2770.

[36] Hayder N., Bouhlel I., Skandrani I., Kadri M., Steiman R., Guiraud P., Mariotte A.M., Ghedira K., Dijoux-Franca M.G., Chekir-Ghedira L. 2008. In vitro antioxidant and antigenotoxic potentials of myricetin-3-o-galactoside and myricetin-3-o-rhamnoside from Myrtus communis: modulation of expression of genes involved in cell defence system using cDNA microarray. Toxicology In Vitro, 22 (3): 567-581.

[37] Rosa A., Deiana M., Casu V., Corona G., Appendino G., Bianchi F., Ballero M., Dessì M.A. 2003. Antioxidant activity of oligomeric acylphloroglucinols from Myrtus communis L. Free Radical Research, 37 (9): 1013-1019.

[38] Rosa A., Melis M.P., Deiana M., Atzeri A., Appendino G., Corona G., Incani A., Loru D., Dessì M.A. 2008. Protective effect of the oligomeric acylphloroglucinols from Myrtus communis on cholesterol and human low density lipoprotein oxidation. Chemistry and Physics of Lipids, 155 (1): 16-23. 
[39] Ines S., Ines B., Wissem B., Mohamed B.S., Nawel H., Dijoux-Franca M.G., Kamel G., Leila C.G. 2012. In vitro antioxidant and antigenotoxic potentials of 3,5-O-di-galloylquinic acid extracted from Myrtus communis leaves and modulation of cell gene expression by $\mathrm{H}_{2} \mathrm{O}_{2}$. Journal of Applied Toxicology, 32 (5): 333-341.

[40] Chen A.Y., Chen Y.C. 2013. A review of the dietary flavonoid, kaempferol on human health and cancer chemoprevention, Food Chemistry, 138 (4): 2099-2107.

[41] Öz S., Çakır Arıca Ș. 2016. Evaluation of antigenotoxic effect of Myrtus communis L. (mytle) fruit extract. International Conference on Natural Science and Engineering (ICNASE'16), pp 2474-2481, 19-20 March, Kilis. 